mansasa

\title{
Benefits arising from lay involvement in community-based public health initiatives: The experience from community nutrition
}

Lynne Kennedy

GlyndwrUniversity, 1.kennedy@glyndwr.ac.uk

Follow this and additional works at: http://epubs.glyndwr.ac.uk/chcr

Part of the Community Health and Preventive Medicine Commons, Health Services Research Commons, Public Health and Community Nursing Commons, and the Public Health Education and Promotion Commons

This is the authors final version of the article. The final, definitive version of this paper has been published in Perspectives in Public Health, 130(4), July 2010 by SAGE Publications. All rights reserved. (C) The published article is available online at http://psp.sagepub.com

\section{Recommended Citation}

Kennedy, L. (2010) 'Benefits arising from lay involvement in community-based public health initiatives: The experience from community nutrition'. Perspectives in Public Health, 130(4), 165-172

This Article is brought to you for free and open access by the Nursing, Medical Sciences and Health at Glyndwir University Research Online. It has been accepted for inclusion in Health Science by an authorized administrator of Glyndŵr University Research Online. For more information, please contact 
ORIGINAL PAPER

Benefits arising from Lay involvement in community based public health initiatives: the experience from community nutrition

Dr Lynne Kennedy MPhil, PhD, RPHNutr. , HonMFPH.,

Senior Lecturer Public Health

School of Health, Social Care and Sport and Exercise Sciences

Prifysgol Glyndŵr Wrecsam

Glyndŵr University Wrexham

Mold Road, Wrexham, Wales. LL1 1 2AW.

Ffon/Tel: $+44(0) 1978293112$

Ffacs/Fax: +44(0) 1978290008

l.kennedy@glyndwr.ac.uk

www.glyndwr.ac.uk 


\section{ORIGINAL PAPER}

Benefits arising from Lay involvement in community based public health initiatives: the experience from community nutrition

\section{Abstract:}

Aims: To explore the experiences of Lay Food and Health Workers (LFHW) and professionals involved in delivering local food and health initiatives, to improve understanding of the perceived benefits associated with their involvement and wider opportunities for promoting health.

Study design: An interpretive qualitative inquiry

Setting: Community-based NHS Lay food and health worker programmes in 16 locations serving less affluent neighbourhoods across England, UK.

Subjects: 29 food and health professionals, 53 LFHW employed by and associated with the management or day-to-day implementation of 16 LFHW initiatives in the study

\section{Findings:}

Salient benefits identified at the level of service, individual lay worker and community: increased service coverage and ability to reach 'hard to reach'; personal development; and enhanced social support. ;

\section{Conclusions}

This study highlights previously unreported benefits related to the direct experiences of lay people utilised within community nutrition in the UK, which go beyond those associated with professional-led initiatives, suggesting the need for adopting a broader view of lay involvement within the UK public health workforce.

Key Words: Lay Health Workers; Health Trainers; Community Health Workers; Social Support; Benefits; Personal Development; Communities

Current Word count: 4300

Intro and background (1000)

Methods 600

Findings 1900

Discussion 680

Conclusions (190) 


\section{Introduction \& Background (970)}

"In our preoccupation with developing professional health-care services we have lost sight of the contribution of lay people to their own health care. Indeed health care has become synonymous with professional care." (Levin, 1986: 285)

By the late $20^{\text {th }}$ century, health systems in western industrialised societies became synonymous with the medical profession and biomedical or 'allopathic' model of health; a system characterised by the emphasis on curative services and treatment of chronic disease, reliant upon professionals for delivery. Societal changes, such as ageing populations and concomitant rising cost of treating chronic diseases, are forcing policy makers to seek cost-effective alternatives (1), including a return to lay involvement in health care and increasing de-professionalisation of health services.

Throughout history lay people have played an important role in both formal and informal systems of health and healing (2). Lay involvement in health and health care is by no means recent. In the 1960's the 'Community Health Worker' (CHW), were utilised, in low to middle-income countries, as a means of increasing access to basic health care services; by the 1980's, support for lay involvement in health care developed in western industrialised countries, and was particularly popular in North America where it had expanded into community-level public health programmes; In 1998, some 12,500 'Lay Health Adviser's' (LHA) were registered (3) with potentially more working in a voluntary capacity. As more recent estimates confirm, lay helping represents a substantial and continuously expanding proportion of the US public health workforce (4). Similarly UK health services have been actively recruiting lay people into roles previously restricted to health professionals. Within Community Nutrition and Dietetics, the 'Community Food Worker' is fairly well established and accepted by professionals (5); whilst in 2003 government advocated the introduction of 'Health Trainers' to supplement the work of professionals (6).

The nature of lay involvement in health and the definitions and terms used varies considerably within and between countries and professional disciplines. The authors of the Cochran review into lay helping in primary care (7) usefully employed the term 'lay health worker' to refer to: 
"Any health worker: carrying out functions related to health-care delivery; trained in some way in the context of the intervention; having no formal professional or paraprofessional certificated or degreed tertiary education." (Lewin et al, 2005: 3)

This resonates with roles adopted by lay people utilised by community nutrition interventions in England, informing the current paper (8). Here, lay involvement was primarily linked to activity targeting lifestyle risk factors as part of broader chronic disease prevention programmes and health promotion initiatives with an emphasis on lifestyle modification and behaviour change; despite claims of a broader approach to health, in practice, fairly narrow education or behavioural approaches to health promotion have dominated the utilisation of lay people in this particular field $(9,10)$.

Theoretical justification for lay involvement in community and public health interventions originates from the health education literature, particularly social support (11-16) including early work in the UK (17). The benefits associated with lay involvement includes diverse range of claims, from assumptions about increased coverage and efficiency of services (18) increased efficacy in changing health related behaviours (19-21) particularly amongst the so-called 'hard-to reach' groups (21), individual or community empowerment $(22,23)$ and advocacy on behalf of socially disadvantaged or ethnic minority communities (24). Evidently, social affinity and unique ability of lay people, particularly those indigenous to the communities served, to disseminate culturally specific messages and help in identifying and overcoming barriers to behaviour change, is key to their success $(25,26,27)$. The evidence base remains equivocal; whilst effectiveness has been demonstrated for some health care initiatives (28), evidence in other areas, particularly public health initiatives, where expansion is greatest, is lacking. Despite this, lay health worker initiatives continue to be implemented. Nonetheless, as the present paper argues, the question of whether lay health workers have a role in UK public health could well be redundant; we should be asking more fundamental questions about what we expect from lay involvement, what the model of helping looks like, and how do we evaluate this, in terms of benefits to individuals and society, more appropriately.

In essence public health claims to be concerned with the health and wellbeing of populations. Health, in its widest sense, is best expressed as a resource that permits people to lead individually, socially and economically productive lives (29). 
The narrow focus on behaviour change and narrow health indicators adopted by many public health researchers is unhelpful therefore in assessing possible benefits. The recent return to policies favouring downstream initiatives, including social marketing, is also counterproductive in establishing benefits across the alternative models of lay helping. Moreover, complex concepts such as health and behaviour are best understood in their social context; methods that enable us to explore the lived experiences of people in the field are more likely to help us understand what is happening and why, yet the majority of published studies into lay helping have adopted a positivist paradigm. Whilst lay involvement in health promotion initiatives may be laudable, attempts to understand and establish the potential benefits is undermined by research that is over reliant upon relatively narrow models of health.

This paper explores the benefits and wider opportunities of lay helping as identified by LFHW and professionals from the field. It draws on qualitative data collected from people directly involved in sixteen different lay initiatives within the field of community nutrition and dietetics in England. The findings of this unique study will inform policy discussions about the wider benefits and opportunities to be gained from lay involvement in similar community health initiatives, especially in socially disadvantaged neighbourhoods, but also the wider health promotion and public health agenda. The paper here is therefore timely and helpful in understanding the potential benefits arising from lay involvement in promoting health, beyond a traditional narrow concept of public health. 


\section{Methods (510)}

The current paper draws upon the findings of a qualitative study conducted in England in 2002-04, in which discourse on experiences around lay involvement in public health is examined, (30). The theoretical orientation and interpretative stance underpinning the methodology is best described as a subtle version of the constructionist approach. Inherent to this was a view that it is possible to explain social life by observing and interpreting human action and discourse.

\section{Sample}

The sampling frame consisted of all food and health initiatives already utilising lay people (paid or unpaid) working in the field in England in 2002/03. These were identified through relevant national databases and professional networks: lay food worker database Bolton Health Care Trust; HDA/Sustain 'Food and Low Income

Project Database'; British Dietetic Association (BDA) Community Nutrition Group, Health Promotion Specialists Network; newsletters targeting community food and health initiatives. Forty eight projects $(n=48)$ met the criteria and were invited to participate; non-responders were followed up by telephone. From this 30 were excluded (10 non-responses, in 20 projects LFHWs were not yet trained/working and therefore ineligible); the study sample therefore consisted of 18 projects, with three lost to attrition. The final study population consisted of 15 initiatives involving 82 respondents, one third $(n=29)$ professionals, primarily $(n=24)$ Community Dietitians (CDs), employed by LFHW projects, and two thirds $(n=53)$ lay people, employed as LFHWs.

\section{Ethical Approval:}

Advice on ethical approval was sought from the University of Liverpool research ethics committee during the original design phase; ethical approval was not required. Guidelines on ethical research conduct (31) however were adopted throughout. 


\section{Data collection \& analysis}

Primary data was collected via semi-structured focus group interviews, because this method combines the benefits of having a template for questioning, whilst also retaining the flexibility of unstructured interviews (32). Where possible participants were interviewed in uni-disciplinary groups to encourage all interviewees to respond on an equal footing. The discussion schedule was developed around respondents experience across four areas: nature of project/activity; LFHW roles and responsibilities; LFHW attributes; perceived benefits and possible challenges.

All interviews were conducted by the principal investigator (LK) (PI) at locations and times convenient to respondents, with access negotiated through project managers. Permission to record interviews and use the data for the purpose of research was obtained at the outset (written consent from the project co-ordinator) and, again, verbally from respondents prior to interview. Interviews were tape-recorded and transcribed verbatim by an external service. The data (transcripts) were analysed according to the five stages of Framework Analysis: familiarisation, identifying a framework, indexing, charting, mapping and interpretation (33). This involved reading all transcripts fully ('familiarisation') to gain a sense of the data (ii) re-reading transcripts in detail, thematically coding data (aided by qualitative software, NUDIST NVIVO, (34) to manage the data), resulting in a thematic framework (LK); (iii) patterns and connections within the data were identified as emerging themes; (iv) the form and nature of categories and concepts, including negative cases, were mapped and, (v) data charts reviewed, in order to interpret the key themes (Figure 1). Each stage of the analysis was discussed amongst the research team to improve rigour.

\section{FIGURE 1 ABOUT HERE}


The findings draw on the raw data, in the form of respondents' feedback and also 'charts' of emerging themes 'captured' during the analysis, in keeping with Framework Analysis. Raw data have been selected if they best articulate the discourse arising in relation to a theme, not because they are unique. Each quotation is anonymised using unique project (Project UI: 01-15) and respondent identifiers: professional (HP); lay (LFHW).

\section{Details of LFHW programmes\& Respondents}

Socio-demographic details of lay workers and LFHW initiatives have been published previously (35). In total 29 professionals and 53 LFHW were interviewed across 15 of the 18 projects identified. Whilst all 15 projects shared a universal goal, to promote healthy eating, this was achieved through a limited range of approaches, characterised by a narrow, individualistic focus. Lay roles spanned three broad areas: nutrition education; health promotion; and administration and personal development. Narratives from both professionals and LFHWs indicated that the primary role for LFHWs was to encourage dietary change by translating complex messages into credible and culturally appropriate advice.

\section{Perceived benefits resulting from Lay Food and Health Worker involvement in promoting healthy eating}

Overall, the most salient benefits identified by informants were 'reaching the hard to reach', cost efficiency, increased service coverage, personal benefits for LFHW themselves and the potential for improving the community (Figure 2). Differences however were observed in the nature of responses voiced by professional and lay informants. Whilst professionals more often volunteered information on the perceived cost-benefits of involving LFHW, with mention of the benefits to LFHW, they talked less about benefits to the local community; whilst LFHW spoke more about perceived benefits to themselves and their clients.

\section{Figure 2 about here}




\section{Opening doors: Contacting the 'hard to reach'}

The term 'hard to reach' is widely used within health promotion to refer to individuals or population groups with whom conventional services find it difficult to engage. The ability of LFHW to engage with people considered 'hard to reach' was a central theme in all informants' accounts:

"[...] We're now finding other groups are getting involved who might not normally do this kind of thing [...] [other professionals] are saying how amazed they are because [whereas] they've not managed to motivate them ['hard to reach'] to do sessions before, but when it comes to the food workers' sessions, people come religiously." [11, HP]

"And I would guess that $97 \%$ of the people that we have worked with would never have seen a nutrition expert in any other capacity." [03, HP]

Respondents attributed this primarily to shared life experiences, and the social and cultural proximity enjoyed by LFHW to communities served in helping overcome social and cultural barriers between formal services and the local community:

"They see you and because we're all mums they think 'they're teaching their kids to eat healthy so we can do it and we can go and ask them, we don't have to make an appointment to see the'. [...] We get stopped in the schoolyard, or walking along the street, rather than having to go through the channels to the health professionals. Obviously they have got to wait for an appointment and then they have got to be seen and assessed, whereas they can just come up to us in the street and say can you give us a hand with this, that is my perception." [10, LFHW]

\section{Value for money}

The second most salient point arising from the data was the discourse on perceived cost-benefits arising from 'substitution' of expensive professionals with LFHW.

"Well again the concept was, this is the money we have and how are we going to divvy it out? If we hired two dietitians that would be four hands on 
deck! If you're talking about being able to employ food workers and they are paid less than dietitians then you can have more of them [...] I think in terms of numbers of bodies around and the number of hands on deck six people can do six times the work that I can do." [03, HP]

Many of the professionals viewed community-based work as intensive and timeconsuming; LFHW involvement therefore was claimed to be less expensive and therefore viable option to professional-led services.

“We like everyone else can't afford enough dietitians and if it's about practical delivery and initiatives, which we know work, then maybe it's about converting some dietetic hours into community food workers." [13, HP]

"It's much better to have a dietitian doing the paperwork, the funding and stuff like that, which needs doing, and the supervising of the projects [...]" [05, HP]

Overall, although most informants were optimistic about service benefits resulting from the introduction of LFHW, projects experiencing high LFHW turnover were highly sceptical.

\section{Improving coverage}

The term 'coverage' refers to the proportion of people reached by a particular service in relation to need. In most Western industrialised countries optimising service coverage is both a political and public health priority. Service coverage featured mainly in discussions with professionals. Nonetheless, most informants believed in a favourable relationship between LFHW involvement in local community dietetic services and increased coverage

"I think the more people you have in that particular capacity the more widely you are going to reach, and the more people you are going to reach [...] The fewer numbers that you have got then you are just not going to reach that number of people." [03, HP]

"We definitely couldn't do what we are doing without them."[09, HP]

$$
-10-
$$


A view recognised amongst the LFHW, albeit more implicitly:

"It is more about how much time they have... with their clinical case load they definitely wouldn't have the time. We've got three workers so if you times eighteen and a half by three it gives you a large number."[A13; LFHW]

In the absence of empirical data it was difficult for any of the informants to comment accurately on levels of coverage before or after LFHW involvement. In summary, there was an assumption amongst both professional and lay informants that LFHW involvement may increase service coverage.

\section{Personal benefits for Lay Food and Health Workers}

All LFHW interviewed could identify at least one positive outcome resulting from their involvement in an initiative (see Figure 3).

\section{Figure 3 about here}

Personal development was the most salient of benefits identified by LFHW and although this took different forms, was most frequently associated with increased sense of self-confidence and self-efficacy, with some evidence of formal qualifications or increased aspirations:

"I've come a long way. I mean six months ago I never dreamt l'd be talking in front of six people or showing people how to eat healthily. Its not been easy mind you, I'd say the training was hard at times. I thought I'm never going to get through all of this." [04, LFHW]

"I would like to probably try different things, I wouldn't mind going into counselling." [07, LFHW]

All professionals liked the idea of LFHW personally benefiting from involvement, and was a source of gratification for them too. 
"If one of them decided they wanted to go off and get another job l'd be only too pleased. These were unemployed women and so to see them moving on and thinking they can get another job and be successful, would to me be recognition that the project has worked well. That is what SRB [funding] is about getting people into employment." [13, HP]

Whilst most projects successfully encouraged personal development, this did vary.

\section{Benefits for communities served by LFHW initiatives}

Both LFHW and professionals readily identified outcomes to communities served (Figure 4).

\section{Figure 4: about here}

Most LFHW informants focused on the wider benefits to community health; potential for LFHW to reduce social isolation, through better systems of social support, was a central theme in their discourse; this was regarded as particularly important because many of the women in contact with them had revealed loneliness and isolation as a major concern.

"I've had ladies come to the class and didn't know one another, and yet they live down the same street [...] They have become lifelong friends afterwards and they spend a lot of time together and so I think it gets rid of a lot of isolation for single mums particularly." [11, LFHW]

Although professionals recognised benefits to the community resulting from increased social support, this was mentioned less frequently in their discourse. Moreover, only minor credit was given to LFHW for their role in benefiting the wider community. In contrast, much of their response focused on benefits associated with their role in encouraging behaviour change.

“We've evaluated the cookery club project and can see evidence of change in diet [...] both during attendance at the club and then six months later. We can see changes in fruit and vegetable consumption, particularly fat 
consumption [...] but we have also captured some evidence of weight change."[02, HP]

Anecdotal evidence suggests that LFHW provide a valuable resource in enhancing client's basic cookery skills, thereby equipping them to prepare healthier meals for their families. Some regarded the LFHW as a catalyst, helping people already interested in adopting a healthier diet change their behaviour

“We've had some good results, people have tried things and they've gone away and said 'we've done that at home'. We've given them the initiative the starting point and they'll try things themselves." [09, LFHW]

Feedback supports the suggestion that LFHW were able to provide clients with practical or instrumental support to help make healthier changes without exacerbating financial barriers .

'Life is so busy especially for young parents, they don't know how to do the quick fixes, you know you can go to a take-away and just buy things and that is it. They don't know how to do quick recipes, so that is where we come in and just give them that little bit of opportunity to explore. At home they may not be able to do that because of wastage and everything. We are giving them the chance to come along to these sessions and just to explore and taste it at the end, if they like it they can adapt it at home. If they don't like it at least they had that chance to taste it" (LFHW)

Given the strength of conviction in LFHW perceptions relating to dietary change this aspect was considered further. Whereas professionals tended to look at any change with regard to the nutritional benefits, LFHW emphasised the wider benefits, especially the importance of individual empowerment and sense of achievement resulting from successfully making smaller more practical changes, benefits possibly underestimated by some professionals:

"The mother in question was actually seeing a dietitian for her son but she didn't have any cooking skills, she was unable to cook. When she came on our course we showed her how to do this and that, the child within a week 
started to show some good signs, just within one week, and she was overjoyed. So we were able to help her." [11, LFHW]

In summary, informants identified direct and indirect benefits resulting from LFHW involvement. The most salient of these are the improvements for client and community, and changes achieved by LFHW themselves: increased self-esteem and self-confidence, local capacity building, and social support. Evidently, justification exists for LFHW in providing practical or instrumental, informational and emotional support at an interpersonal level. Although LFHW may provide an important source of social support, this potential was not fully recognised by professionals here. 


\section{Discussion (680 830)}

Benefits associated with LFHW involvement have been identified under three main themes, benefits to: the service or organisation, personal benefit to the LFHW and benefits to the wider community. Benefits referred to by respondents is contextually specific and are associated with preconceived ideas about the role or purpose of the lay helper, which, in England, emphasis remains embedded in traditionally narrow models of health.

\section{Benefits to service}

Overall, professionals perceived LFHW role as providing a vehicle for reaching underserved populations, which resonates with the rationale emerging around LFHW and other forms of lay helping in the UK, including the Health Trainer (36). A view supported by international literature, which asserts that using people indigenous to the communities served, increase chances of accessing social networks inherent to that community or social group; evidently, their ability to relate with like-minded people from their own social networks allows them to 'open doors' enhancing communication and providing social support (37-40). Arguably, success in terms of the benefits and (health) needs identified by a community - is reliant upon lay people retaining a relatively autonomous position, out with a particular organisation.

Despite limited empirical evidence, most professionals felt LFHW involvement would produce cost savings, improve efficiency and reduce pressure on existing staff. In some cases, funding ring-fenced for employing a single clinician (Dietitian) was redirected to employ several LFHW; with the assumption that skill mix (Dietitians and LFHW) brings financial savings, liberating professionals to spend more time on strategic and clinical duties. A view echoed in the wider literature $(41,42)$.

Others were sceptical of claims relating to increased coverage or efficiency. Concerns emerged that some LFHW may work selectively, i.e. 'cherry-picking' clients, whilst others talked of 'hidden costs' associated with recruitment, training and attrition. These and other issues are explored in a forthcoming paper.

Nonetheless, LFHW were confident of the benefits resulting from skill mix and believed they offered a suitable alternative to professional-only delivered services. In the absence of any guidance or national consensus as to the levels of coverage 
expected from LFHW, compared to professional services, it is difficult to conclude, and clearly warrants further investigation.

\section{Personal benefits}

It seems likely that LFHW involvement in health promotion initiatives brings personal and educational benefits. It is also positive that professionals recognise the potential for LFHW as a vehicle for local empowerment and not just a resource for health professionals, which confers with reports (43) (44). In addition to baseline knowledge or skills, other factors influence the levels of personal development in individual LFHW, including social background, prior educational attainment and personal motivation; Others were perplexed by the tension between personal development of LFHW and progression, leading to higher turnover, matters that warrant further consideration.

\section{Benefits to wider community - resource for change; social support}

The discourse amongst professionals clearly suggests that LFHW are primarily viewed as 'agents of change' Hence, benefits were articulated in terms of evidence of accomplishing change in peoples (communities) dietary habits and attainment of indicators adhering to lifestyle and disease prevention. Although evidence that lay health workers can influence lifestyle exists few studies have demonstrated long term effects. Moreover, even projects described as Community Development were primarily interested in changing dietary behaviour; at the expense of empowerment and structural change. At least in the UK, the medical model still dominates local health promotion initiatives around food and health. It was refreshing however to note how LFHW themselves were more interested in pursuing wider benefits, such as their role in providing social support, overcoming barriers to accessing services, and individual empowerment. Thus, they were much more in keeping with the broad definitions of health and health promotion as a resource for living not just in terms of changing lifestyles. This resonates strongly with the work on lay helping in the US, where the original emphasis on increasing opportunities for social support, not extension of professional health services is the primary objective (45) Israel; Schultz).

From a public health perspective the challenge remaining is to explore how lay involvement in community initiatives can truly benefit community or public health. Health is defined as a resource for living not just an endpoint. As the findings here 
suggest unless the wider benefits of lay involvement, beyond lifestyle change, such as social support and empowerment have the opportunity to be explored more fully then their true potential may not be realised. Others might argue that formalising this kind of helping, particularly social support, may institutionalise previously accessible informal support and thereby disadvantage the communities they wish to serve.

\section{Conclusions (190 242)}

There are many tangible and intangible benefits resulting from lay involvement in food and health initiatives in the UK. Besides more obvious benefits to the individual LFHW, in terms of personal development, increased self-confidence and self esteem; benefits to the organisation in terms of potential savings on staff budgets resulting from complimentary skill-mix of professional and lay involvement; and benefits to communities served, through practical support for dietary change and social support both in undertaking change but also in accessing services. Indeed, a major theme is the role of lay people as 'culturally acceptable vehicles for change'. Public health is continuously searching for more effective (and efficient) means of encouraging healthy lifestyle behaviours. Evidence of the extent that such benefits are achievable, and consideration of the costs incurred, is however required. In doing so we need to be mindful of the way in which benefits arising from public health programmes are defined and measured. There needs to be a shift away from narrow behavioural models of lay helping and disease orientated measures of success to broader models of health based on social change; where the goal is increased community capacity and competence and not just health and lifestyle changes - allowing the more important benefits of lay involvement to be appreciated. It may be the extent to which formal or informal helping features within the role that appears to be the defining feature of lay helping and the potential benefits to services, individuals and communities. 


\section{REFERENCES}

1. Wanless D (2002) Securing our future health: taking a long term view. HM Treasury Dept. TSO, London.

2. Friedson, $E$ (1977) The Future of Professionalisation: Chapter 1; In: Stacey M, Reid M, Heath, C and Dingwall R. (Ed.) Health and the Division of Labour. The British Sociological Association. London: Croom Helm. 1977 pp 14-38

3. Rosenthal EL, Wiggins N, Brownstein JN, Johnson S Borbon IA, Rael R. The final report of the National community Health Advisor Study. The University of Arizona, 1998.

4. CDC, (2005) US Centre for Disease Control. Lay Health Advisors.

5. British Dietetic Association (2007) Workforce Census 2006. Birmingham British dietetic Association

6. Department of Health $\mathrm{DH}, 2003$, Tackling Health Inequalities: A programme for Action. London, Department of Health.

7. Lewin SA, Dick J, Pond P, Zwarenstein M, Aja G, Wyk B, Bosch-Capblanch, $X$ and Patrick $M(2005)$ Lay health workers in primary and community health care. The Cochrane Collaboration, John Wiley \& Sons: London.

8. Kennedy $L$ (2006) Development of the Lay food \& Health Worker Role in England: Experiences from the Field. PhD Thesis. University of Liverpool, Liverpool, UK.

9. Kennedy LA, Milton B \& Bundred P (2008) Lay Food \& Health Worker (LFHW) Involvement in Community Nutrition and Dietetics in England: definitions from the field. Journal of Human Nutrition and Dietetics 2008 The British Dietetic Association Ltd 2008 J Hum Nutr Diet, 21, pp. 196-209

10. Kennedy LA, \& Milton B Lay Food \& Health Worker (LFHW) Involvement in Community Nutrition and Dietetics in England: Roles, responsibilities and relationship with professionals Journal of Human Nutrition and Dietetics 2008 The British Dietetic Association Ltd 2008 J Hum Nutr Diet, 21, pp. 210-224

11. Salber, E (1979) The lay advisor as a community health resource. J. Health Politics Policy Law 3 469-79

12. Eng, E, Hatch J, and Callan, A. (1985). Institutionalising social support through the church and into the community. Health Educ. Q. 12 (1) 81-92

13. Israel, BA (1985) Social networks \& social support: implications for natural helper and community level interventions. Health Education Q. 12 (1): 65-80, 1985

14. CDC (1994) Community Health Advisers: Models, Research and Practice, Atlanta, GA, US Department of Health and Human Services; Centre for Disease Control (CDC)

15. Gottlieb, BH (1981). Preventive interventions involving social networks and social support. In B.H. Gottlieb (Ed.) Social networks and social support. Beverly Hills, CA, Sage.

16. Gottlieb BH, (1985) Social Networks and social support: an overview of research, practice and policy implications, Health Education Quarterly, 12: 522

17. Lewin SA, Dick J, Pond P, Zwarenstein M, Aja G, Wyk B, Bosch-Capblanch, $X$ and Patrick $M(2005)$ Lay health workers in primary and community health care. The Cochrane Collaboration, John Wiley \& Sons: London. 
18. Domke, HR and Goffey, G. (1966). The neighbourhood based public health worker: additional manpower for public health services. Am. J. Public Health: 56: 603-08

19. Giblin, PT (1989): Effective utilization of indigenous health care workers. Public Health Rep 104(4): 361-67

20. Eng, E and Young R. (1992) Lay Health Advisers are community change agents. Family and Community Health 15 (1) 24-40, 1992

21. Foley, RM and Pollard CM. (1998) Food Cents-implementing and evaluating a nutrition education project focusing on value for money. Aust. NZ. J. Public Health 22 (4): 494-501

22. McQuiston C \& Flaskerud JH, (2003) "If they don't ask about condoms, I just tell them": A descriptive case study of Latino Lay Health Advisers' helping activities. Health Education \& Behaviour 30 (1): 79-96

23. Duan, Fox SA, Derose KP, Carson S (2000) Maintaining mammography adherence through telephone counselling in church based trial. Am J Public Health $90 ; 1468-71$

24. Plescia M and Groblewski M (2005) A community-based partnership to address barriers to physical activity in African American Community Prev Chronic Dis 20052 (2): 1-2

25. Eng E, Parker, E and Harlan, C. (1997). Lay health advisor intervention strategies: a continuum from natural helping to paraprofessional helping. Health Education \& Behaviour 24 (4) 413-417

26. Heaney, CA and Israel, BA (1997). Social networks and social support in health education. In: Glanz K, Lewis, FM and Rimmer BK (Ed): Health Behaviour and Health Education $2^{\text {nd }}$ edition, San Francisco, Jossey-Bass, 1997, pp 179-205

27. Salber, E (1979) The lay advisor as a community health resource. J. Health Politics Policy Law 3 469-79

28. Lewin SA, Dick J, Pond P, Zwarenstein M, Aja G, Wyk B, Bosch-Capblanch, $X$ and Patrick $M(2005)$ Lay health workers in primary and community health care. The Cochrane Collaboration, John Wiley \& Sons: London.

29. WHO (1986) Ottowa Charter on Health Promotion. WHO, Geneva.

30. Kennedy L (2006) Development of the Lay food \& Health Worker Role in England: Experiences from the Field. PhD Thesis. University of Liverpool, Liverpool, UK.

31. Hek G, Judd, M and Moule P. (1996) 'A framework for ethical research' In: Making sense of research: an introduction for nurses. London: Cassell

32. Fleeman, N and Keeling P. (1995) Guidance notes: running groups on a focused topic of interest. Focus Groups, Observatory Guidance Notes Series, No.1, December 1995, Public Health Observatory, the University of Liverpool, UK

33. Ritchie and Spencer, 1994:178) Ritchie and Spencer, 1994:178 Ritchie, J and Spencer L (1994). Policy Research. In: Bryman A \& Burgess R (eds) Analysing Qualitative Data. Routledge; London. 1994 pp: 173-94

34. QSR (2000) NUDIST NVIVO 1.2 for Microsoft Windows. QSR Software, Australia.

35. Kennedy LA, Milton B \& Bundred P (2008) Lay Food \& Health Worker (LFHW) Involvement in Community Nutrition and Dietetics in England: definitions from the field. J Hum Nutr Diet, 21, pp. 196-209

36. Visram S, Drinkwater C. Health Trainers: A Review of the Evidence. Northumbria University: Newcastle, 2005

37. Schultz AJ, Israel BA, Becker, AB and Hollis RM (1997). "It's a 24 hour thing...living-for-each-other concept": Identity, networks, and community in 
an urban village health worker project. Health Education \& Behaviour, 24 (4): $465-80$

38. Hanrahan, M and Prinsen B. (1997). (Ed) Community Health, Community Care, Community Support. Proceedings of the invitational conference on innovative childhood care and development programs. Netherlands Institute of Care and Welfare MIM Cooperative. NIZW. 1997.

39. Birmingham Community Nutrition and Dietetic Department. Birmingham Food Net Evaluation Report. Birmingham: Birmingham Community Nutrition and Dietetic Department, 2005

40. South J, Woodward J, Lowcock D. New beginnings: stakeholder perspectives on the role of health trainers. The Journal of the Royal Society for the Promotion of Health 2007; 127(5): 225-230

41. Landon B, Loudon J, Selle M, Doucette S (2004) Factors influencing the retention and attrition of community health aides/practitioners in Alaska. $J$ Rural Health. 20(3):221-30

42. Jackson, EJ and Parks C.P (1997) Recruitment and training issues from selected Lay Health Advisor programs among African Americans: a 20-years perspective. Health Education \& Behaviour 24 (4) 418-31

43. Ramirez-Valles J (1998) Promoting health, promoting women: the construction of female and professional identities in the discourse of community health workers. Soc Sci Med. 1998; 47 (11): 1749-62

44. Ramirez-Valles J (1999) Changing women: the narrative construction of personal change through community health work among women in Mexico. Health Educ Behav, 26 (41): 25-42

45. Schultz AJ, Israel BA, Becker, AB and Hollis RM (1997). "It's a 24 hour thing...living-for-each-other concept": Identity, networks, and community in an urban village health worker project. Health Education \& Behaviour, 24 (4): $465-80$ 


\section{FIGURES \& TABLES}

Figure1: Summary of key themes, coding categories: NVivo tree nodes and sibling nodes, relating to examination of the terms and definitions of lay helping within Community Dietetics in the NHS

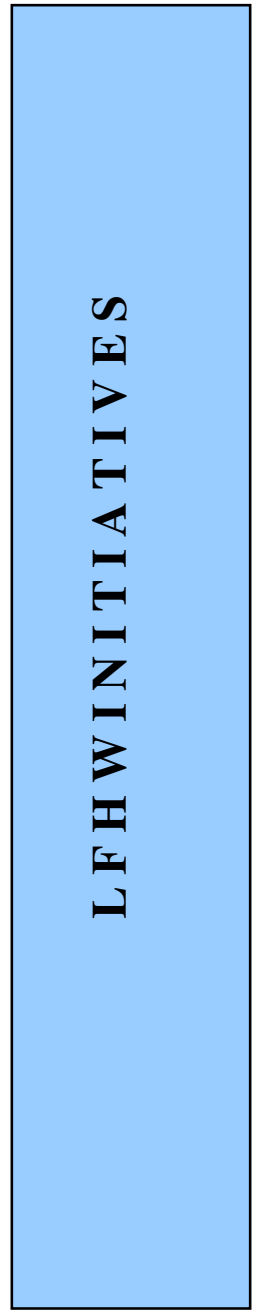

\section{PROJECT}

CHARACTERISTICS

LFHW

ATTRIBUTES

FACTORS

DRIVING

DEVELOPMENT
Background to initiative

Goals

Organisational philosophy

Strategies/Approaches

used

Terms used

Informing

Enabling

Educating

Outreach

Awareness Raising

Supporting

Credibility

Approachable

Local knowledge

Communication

Shared backgrounds

Emvathv

Public health policies

Dietetic shortages

Skill mix

Cost-cutting

Changing roles

Complex issues 
Figure 2: Key Themes: Perceived benefits resulting from Lay Food and Health Worker involvement in promoting healthy eating (Chart 4)

\section{Perceived benefits to service}

Extend existing services

Increase service coverage

Reach 'hard to reach'

Manage workloads

Improve efficiency

Release professionals to do other things (e.g. management, clinical work)

Relieve pressure on other staff

Support health promotion principles and approach

Facilitate community involvement

Help address social exclusion

\section{Perceived benefits to LFHW}

Personal development

Lead to employment opportunities

Encourage return to study

Increased self-confidence and self-esteem

Individual empowerment

\section{Perceived benefits to the community}

Capacity building

Raised awareness of the link between diet and health

Encouraging healthy eating and improve diets

Support individual \& community lifestyle changes to improve health

Community empowerment 
Figure 3: Perceived benefits to LFHW

Personal development

Lead to employment opportunities

Encourages return to study

Increases self-confidence and self-esteem

Individual empowerment

(Extracted from Chart 4; in Figure 2) 
Figure 4: Perceived benefits to the community

Local capacity building

Raise awareness of the link between diet and health

Improve diets

Support individual and community lifestyle changes to improve health Community empowerment

(Extracted from Chart 4; in Figure 2) 
Table 1: Four main areas of LHW activity

1) Increasing access to health care by bridging the gap between social and cultural groups and formal health services

2) Reducing health-care costs by encouraging the appropriate use of the health-care systems

3) Improving the quality of health care by educating health-care providers to the community's health-care needs and enabling patients by fostering self-efficacy

4) Strengthening local economies by linking families to much needed services, mobilising communities to seek resources to meet their health needs

(After: Rosenthal, 1998) 